\title{
Volumes, outcomes, and complications after surgical versus endovascular treatment of aneurysms in the United States (1993-2015): continued evolution versus steady-state after more than 2 decades of practice
}

\author{
Pedram Golnari, MD, 1,2 Pouya Nazari, MD, ${ }^{1,2}$ Roxanna M. Garcia, MD, MS, MPH, ${ }^{1}$ \\ Hannah Weiss, BA, ${ }^{1}$ Ali Shaibani, MD, ${ }^{1,2}$ Michael C. Hurley, MD, ${ }^{1,2}$ Sameer A. Ansari, MD, PhD, ${ }^{1,2}$ \\ Matthew B. Potts, MD, ${ }^{1,2}$ and Babak S. Jahromi, MD, PhD',2 \\ Departments of ${ }^{1}$ Neurological Surgery and ${ }^{2}$ Radiology, Northwestern Memorial Hospital, Northwestern University Feinberg \\ School of Medicine, Chicago, Illinois
}

\begin{abstract}
OBJECTIVE Adoption of endovascular treatment (EVT) and other advances in aneurysm care have shifted practice patterns of cerebral aneurysm treatment over the past 2 decades in the US. The objective of this study was to determine whether resulting trends in volumes, outcomes, and complications have matured in general practice or continue to evolve.
\end{abstract}

METHODS Data were obtained from the National Inpatient Sample from 1993 to 2015. ICD-9 codes were used to estimate annual volumes, outcomes, and complications following treatment of ruptured and unruptured aneurysms. Univariate and multivariate analyses were used to estimate risk ratios for complications and outcomes. Trends in time were assessed utilizing annual percentage change (APC).

RESULTS The authors found a nearly 5 -fold increase in annual admissions with diagnoses of unruptured aneurysms, whereas SAH volume increased less than $50 \%$. Clipping ruptured aneurysms steadily declined (APC $-0.86 \%, p=0.69$ until 1999, then $-6.22 \%, p<0.001$ thereafter), whereas clipping unruptured aneurysms slightly increased (APC $2.02 \%$, $p<0.001$ ). EVT tripled in 2002-2004 and steadily increased thereafter (APC 7.22\%, $p<0.001$ and $5.85 \%, p=0.01$ for unruptured and ruptured aneurysms, respectively). Despite a 3 -fold increase in both diagnosis and treatment of unruptured aneurysms, the incidence of SAH remained steady at 12 per 100,000 persons per year (APC 0.04\%, $p=0.83$ ). In contrast, SAH severity increased over time, as did patient age and comorbidities (all $p<0.001$ ). SAH led to nonroutine discharge more frequently over time after both EVT and clipping (APC 1.24\% and 1.10\%, respectively), although mortality decreased during the same time (APC $-2.48 \%$ and $-1.44 \%$, respectively). Complications were more frequent after clipping than EVT, but this differential risk diminished during the study period and was less perceptible in ruptured aneurysms. The proportion of patients discharged home after treatment of unruptured aneurysms was significantly lower ( $\mathrm{p}$ $<0.001$ ) after clipping $(69.3 \%-79.5 \%)$ than EVT $(88.3 \%-93.3 \%)$; both proportions changed minimally since 1998 (APC $-0.39 \%, p=0.02$, and APC $-0.11 \%, p=0.14$, respectively).

CONCLUSIONS EVT volume markedly increased for ruptured and unruptured aneurysms from 1993 to 2015, whereas clipping decreased for ruptured and slightly increased for unruptured aneurysms. The incidence of SAH remained unchanged despite increased diagnosis and treatment of unruptured aneurysms. In ruptured aneurysms, SAH severity has increased over time, as have age, comorbidities, and nonroutine discharges. In contrast, routine discharge after treatment of unruptured aneurysms remains largely unchanged since 1998 and remains lower with clipping.

https://thejns.org/doi/abs/10.3171/2019.12.JNS192755

KEYWORDS cerebral aneurysm; subarachnoid hemorrhage; endovascular treatment; microsurgical clipping; vascular disorders

ABBREVIATIONS $\mathrm{AHRQ}=$ Agency for Healthcare Research and Quality; $\mathrm{APC}=$ annual percentage change; $\mathrm{aRR}=$ adjusted RR; CSC = Comprehensive Stroke Center; $\mathrm{ECI}=$ Elixhauser Comorbidity Index; EVD = external ventricular drain; EVT = endovascular treatment; HCUP = Healthcare Cost and Utilization Project; ICD-9-CM = International Classification of Diseases, Ninth Revision, Clinical Modification; ISAT = International Subarachnoid Aneurysm Trial; ISUIA = International Study of Unruptured Intracranial Aneurysms; $\mathrm{NI}=$ neurointerventionalist; NIS = National Inpatient Sample; NIS-SSS = NIS-SAH Severity Score; RR = risk ratio; SAH = subarachnoid hemorrhage . SUBMITTED October 13, 2019. ACCEPTED December 2, 2019.

INCLUDE WHEN CITING Published online February 7, 2020; DOI: 10.3171/2019.12.JNS192755. 
$\mathrm{T}$ HE International Subarachnoid Aneurysm Trial $(\text { ISAT })^{26}$ compared mortality and clinical outcomes of patients with aneurysmal subarachnoid hemorrhage (SAH) following either endovascular treatment (EVT) or microsurgical clipping. Published in 2002, the ISAT reported an absolute risk reduction of $6.9 \%$ of death or dependence at 1 year favoring EVT for ruptured aneurysms. Analogous results were published a year later for unruptured aneurysms when the International Study of Unruptured Intracranial Aneurysms (ISUIA), ${ }^{45}$ a nonrandomized prospective study, reported lower 30-day and 1-year overall morbidity and mortality rates for EVT compared to surgical repair in patients with unruptured aneurysms. As a result, a substantial increase in EVT occurred, leading to a large shift in treatment of cerebral aneurysms from clipping to EVT. While prior work has examined how this shift to EVT has affected volumes and outcomes in practice at specific time periods, $, 32,31$ it remains unclear whether this decades-long shift in practice has plateaued or whether outcomes and complication rates continue to evolve. Additionally, such trends can be expected to have far-reaching implications, affecting such things as metrics for neurosurgical resident training, ${ }^{29}$ criteria for Comprehensive Stroke Center (CSC) certification, ${ }^{18}$ and eventually the incidence of aneurysmal SAH itself. Given that we now have more than 2 decades of longitudinal practice data across the US recorded in the National (Nationwide) Inpatient Sample (NIS), we examined trends in the treatment of patients with cerebral aneurysms and their clinical outcomes across the longest period conducive to uniform definitions and methodology (1993-2015). We aimed to show current treatment of brain aneurysms and SAH in the context of change over time, and to determine if trends over the past 2 decades indicate a continued shift versus a maturation of practice with respect to volumes, outcomes, and complication rates.

\section{Methods \\ Database}

The NIS database contains all-payer data on hospital inpatient stays from states participating in the Healthcare Cost and Utilization Project (HCUP) sponsored by the Agency for Healthcare Research and Quality (AHRQ) and the US Department of Health and Human Services (Supplementary Methods). Annual NIS data sets from 1993 to 2015 were obtained from the HCUP Central Distributor. To produce national estimates, discharge weights provided by the AHRQ website (TRENDWT prior to 2012 and DISCWT after 2012) were used. ${ }^{16}$ Age-standardized incidence rates of unruptured aneurysms and SAH were estimated using the US census data from 1993 to $2015 .{ }^{41}$ Hospital teaching status and size were defined by the NIS. This project was exempt from IRB review.

\section{Patient Selection and Endpoint Variables}

The International Classification of Diseases, Ninth Revision, Clinical Modification (ICD-9-CM) code sets were used to define medical diagnoses, inpatient procedures, complications, and adverse events (Supplementary Table 1). ${ }^{6,22,31,36}$ All patients diagnosed with an unruptured aneurysm or SAH were included in the study. Treatment procedures were microsurgical clipping or EVT. Patients with both EVT and clipping procedure codes in the same admission were excluded in the analysis. In the NIS database, the first listed diagnosis is the principal diagnosis, defined as the condition established to be chiefly responsible for the admission of the patient to the hospital for care ${ }^{14}$ However, by only using the first/principal diagnosis field for selection of patients in the NIS with a diagnosis of $\mathrm{SAH}$, we might miss patients whose initial diagnosis was miscoded or was not SAH, yet who nevertheless had a ruptured aneurysm treated during that hospitalization. This could also lead to a systemic bias in not including certain severities or types of SAH presentation. Indeed, we found that by only utilizing the first diagnostic field, we would miss between $5 \%$ and $10 \%$ of all treated ruptured aneurysms every year in the NIS. This was also true for procedure variables. Excluding such patients could therefore impact outcomes results as well as the overall epidemiology and longitudinal changes in SAH during the study period. Thus, publications based on the NIS database using only the first diagnosis and procedure variables ${ }^{3,31}$ may have underestimated the frequencies and incidences due to omitting patients who have had their aneurysms treated but did not list an aneurysm or SAH as their first diagnostic code. We therefore included all aneurysm diagnoses and procedures in the NIS without restricting our analysis to the first listed code. This approach has also been taken by Shea et al. ${ }^{36}$ who, similarly to us, searched across all diagnosis fields for SAH while excluding patients who had a concomitant diagnosis matching trauma, cerebral arteritis, or arteriovenous malformation.

The total number of comorbidities was analyzed using the Elixhauser Comorbidity Index (ECI) score (minimum $=0$, maximum $=29) \cdot{ }^{10}$ Severity of SAH was adjusted for by the NIS-SAH Severity Score (NIS-SSS; Supplementary Methods). ${ }^{43}$

Due to changes in NIS database design, we were unable to distinguish discharges to rehabilitation from those discharged to skilled nursing facilities or hospice (Supplementary Methods). We therefore categorized outcome data as 1) routine discharge (typically home), 2) death, or 3) nonroutine discharge (discharge to short-term hospital, inpatient rehabilitation facility, intermediate care facility, skilled nursing facility, or hospice) using the NIS DISP (1993-1997) and DISPUNIFORM (1998-2015) data fields. This was done to provide a uniform definition across the entire study period. An additional analysis was undertaken to estimate palliative (vs nonpalliative) discharges by combining the ICD-9-CM code for palliative care (v66.7) with those for nonroutine discharges.

\section{Statistical Analysis}

Differences in patient and hospital characteristics by diagnostic and treatment groups and outcomes were examined using the chi-square test for categorical variables and the Student t-test and ANOVA for continuous variables. Temporal trends were assessed 1) over the entire time period by annual percentage change (APC) estimates using the Joinpoint Regression Program (version 4.6.0.0, Statistical Methodology and Application Branch, Surveillance Re- 
A

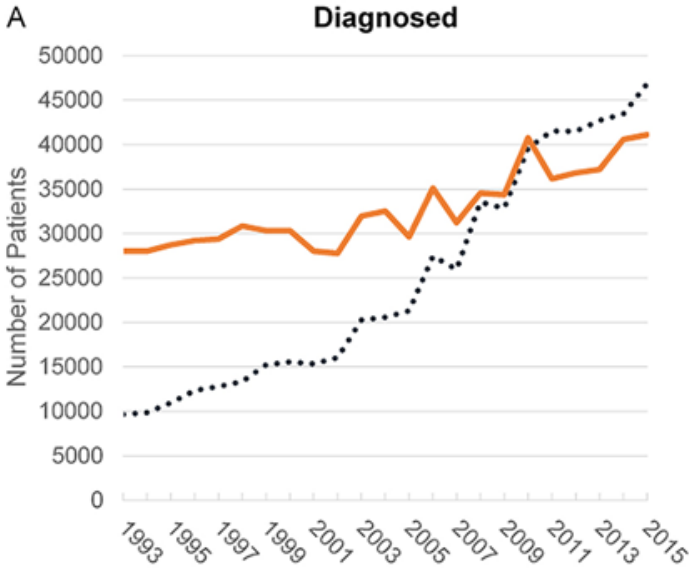

B

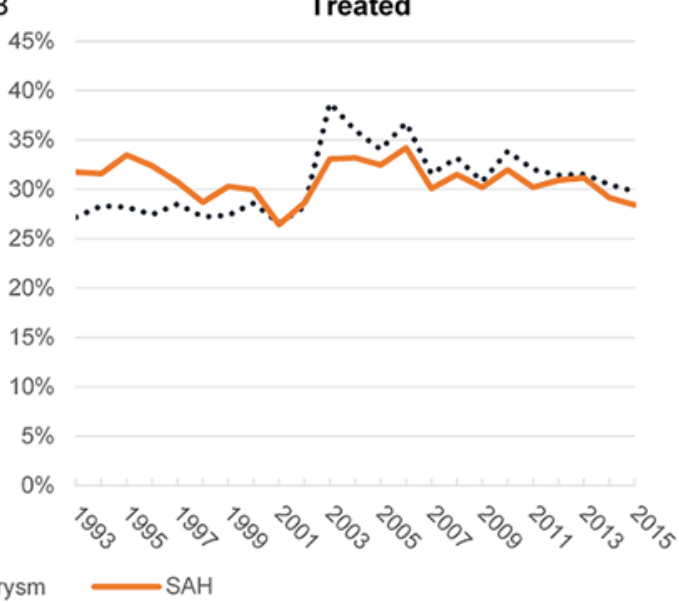

C

...... Unruptured Aneurysm

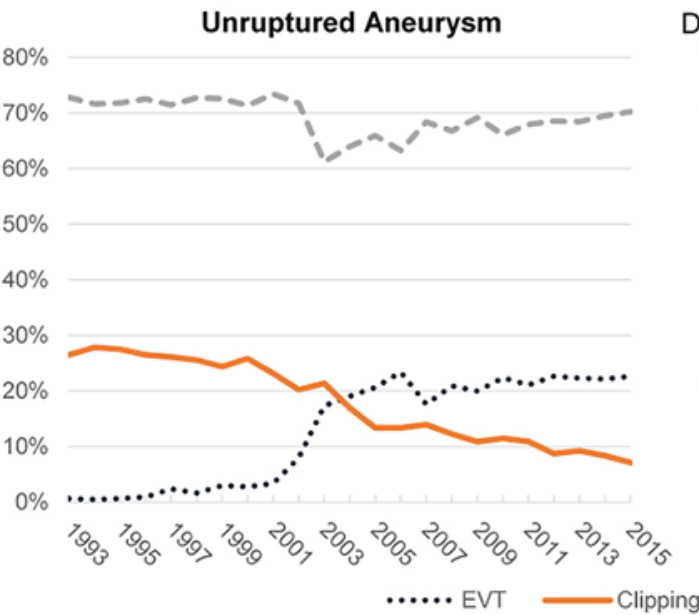

$$
\text { D }
$$
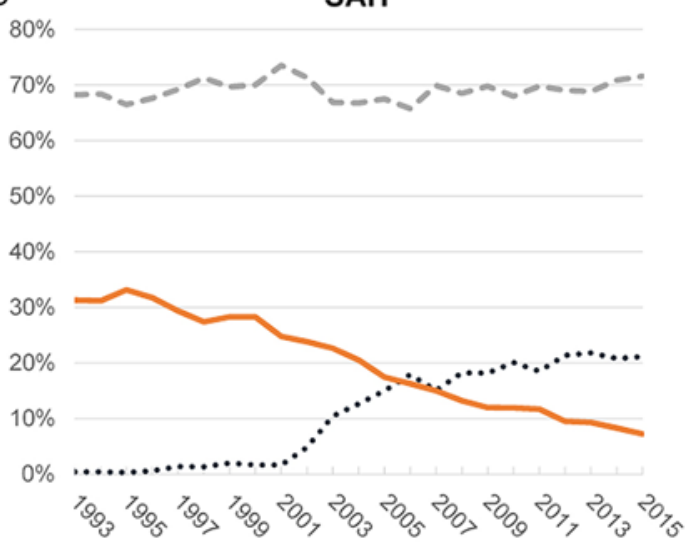

FIG. 1. Hospital admissions with diagnosis of unruptured aneurysm versus $\mathrm{SAH}(\mathbf{A})$, percentage of treated patients $(\mathbf{B})$, and proportion of treatment modalities in each group (C and D), from 1993 to 2015. Figure is available in color online only.

search Program, National Cancer Institute), ${ }^{21}$ and 2) using three representative 3 -year epochs derived from combining data from the beginning of the study period prior to publication of the ISAT (1999-2001), after the publication of the ISAT (2003-2005), and at the end of the study period (2013-2015). Poisson regression ${ }^{48}$ was performed with the use of generalized estimating equations and clustering at the hospital level, and unadjusted risk ratios (RRs) were obtained for discharge disposition, procedure complications, and adverse events in EVT versus clipping. Additionally, adjusted risk ratios (aRRs) were obtained for factors associated with routine discharge and hospital mortality. The adjusted model included terms for age group, sex, race, household income, health insurance, hospital characteristics (teaching status, region, and size), ECI score, and treatment modality. Statistical analysis was performed using IBM SPSS Statistics for Windows (version 25, IBM Corp.). A p value $<0.05$ was defined as statistically significant.

\section{Results}

\section{Trends in Volumes Over Time}

From 1993 to 2015, 568,750 discharges of unruptured aneurysms and 752,690 discharges of SAH were identified (Supplementary Table 2). In both groups, the majority of patients were 50-64 years of age, female, and white. More than two-thirds of cases were admitted to teaching and large-sized hospitals. The volume of hospital admissions with a diagnosis of an unruptured aneurysm increased nearly 5-fold from 1993 to 2015 (APC 8.08\%, 95\% CI $7.52 \%-8.66 \%, \mathrm{p}<0.001)$, whereas there was less than a $50 \%$ increase in admissions for $\mathrm{SAH}$ over the same time period (APC 1.78\%, 95\% CI 1.37\%-2.19\%, p < 0.001). Overall, admissions with a diagnosis of aneurysm (unruptured or ruptured) led to treatment in $26.5 \%-38.7 \%$ of patients (Fig. 1A and B).

Despite increasing numbers of admissions with a diagnosis of unruptured aneurysm or SAH, the overall proportion of patients treated at the same hospitalization remained largely similar from 1993 to 2015 (barring a transient uptick after publication of the ISAT): $27.2 \%-29.8 \%$ in unruptured and $31.7 \%-28.4 \%$ in ruptured aneurysms (Fig. 1B). In contrast, there was a substantial shift in treatment modality during the same time period. In 1993, nearly all unruptured and ruptured aneurysms were treated by microsurgical clipping. A shift in the proportion of 

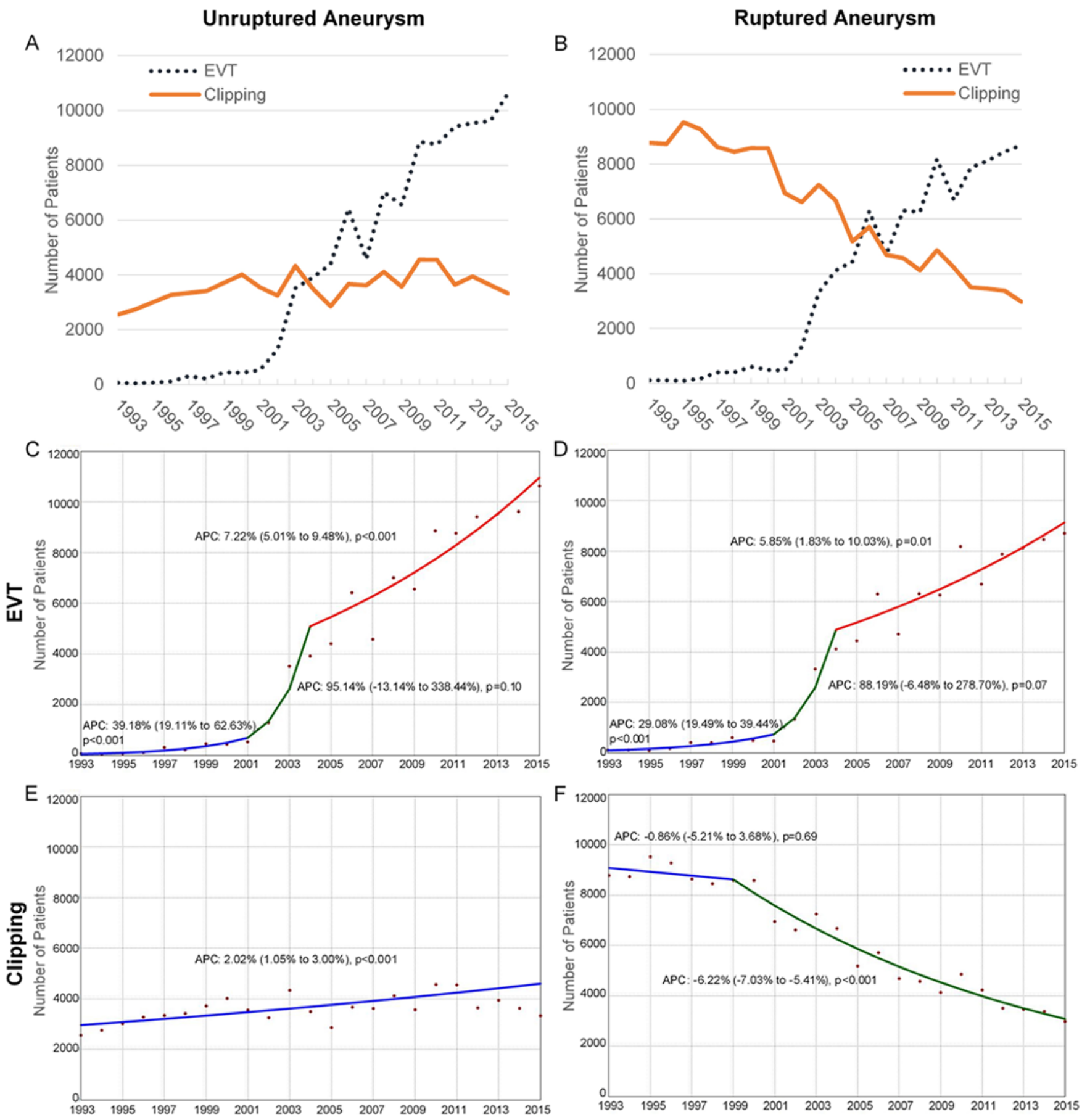

FIG. 2. Admissions with treatment of unruptured (A) and ruptured (B) aneurysms, and their respective APCs (C-F), from 1993 to 2015. Figure is available in color online only.

aneurysms treated with EVT instead of clipping began in 2001 in both the ruptured and unruptured groups. As a result, the dominant mode of treatment eventually reversed in both groups, with EVT dominating in 2004 for unruptured aneurysms (Fig. 1C) and in 2006 for ruptured aneurysms (Fig. 1D).

The main reason behind this relative shift in treatment modality appears to have been an increase in the absolute number of aneurysms treated yearly by EVT during the study period, in both unruptured and ruptured aneurysms (Fig. 2A and B). This increase was particularly notable in 2002-2004 when there was a nearly 3-fold increase in admissions for EVT (for both ruptured and unruptured aneurysms) following publication of the ISAT. After 2004 this increase continued with an APC of $7.22 \%(95 \%$ CI $5.01 \%-9.48 \%, \mathrm{p}<0.001)$ in unruptured and $5.85 \%(95 \%$ 

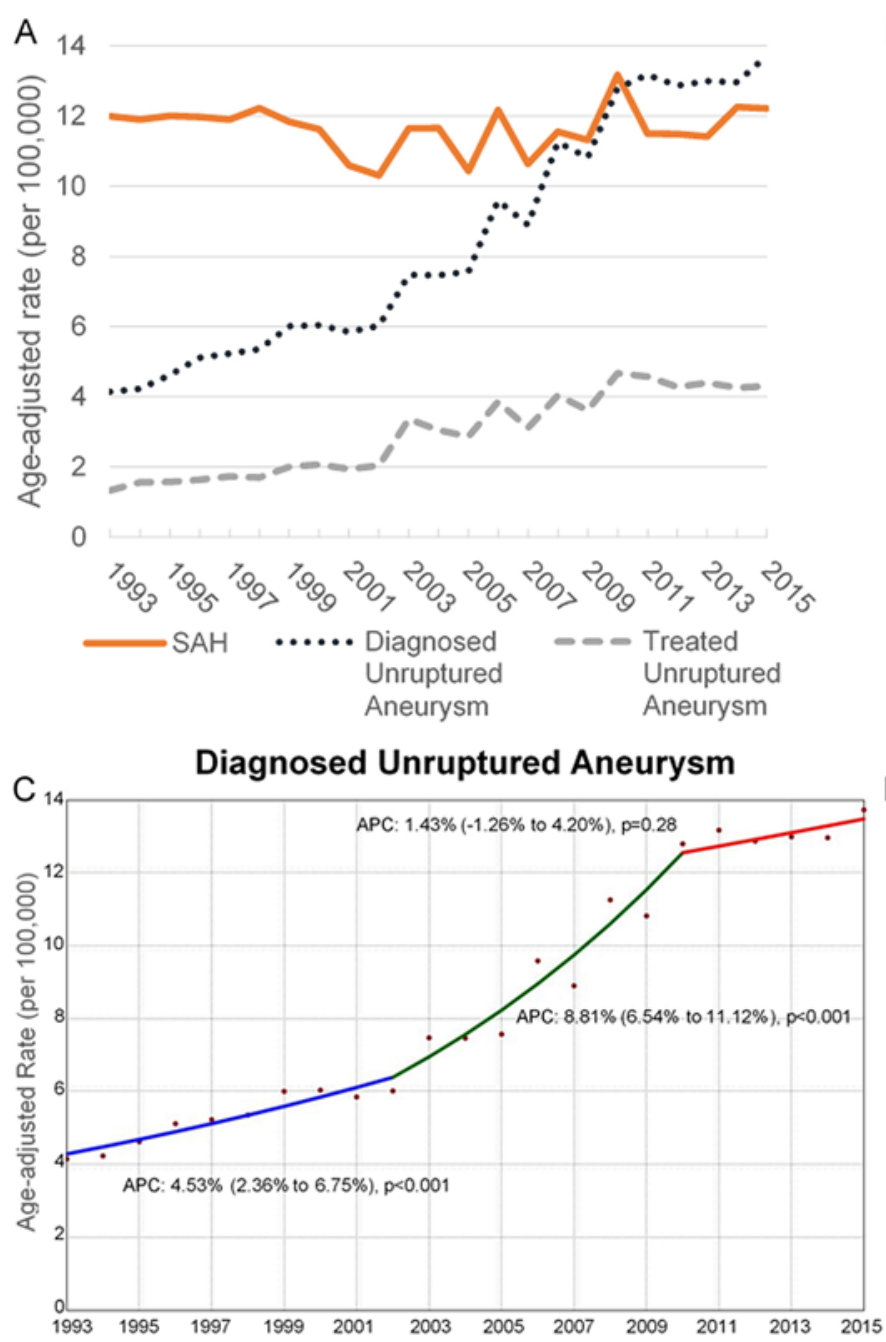
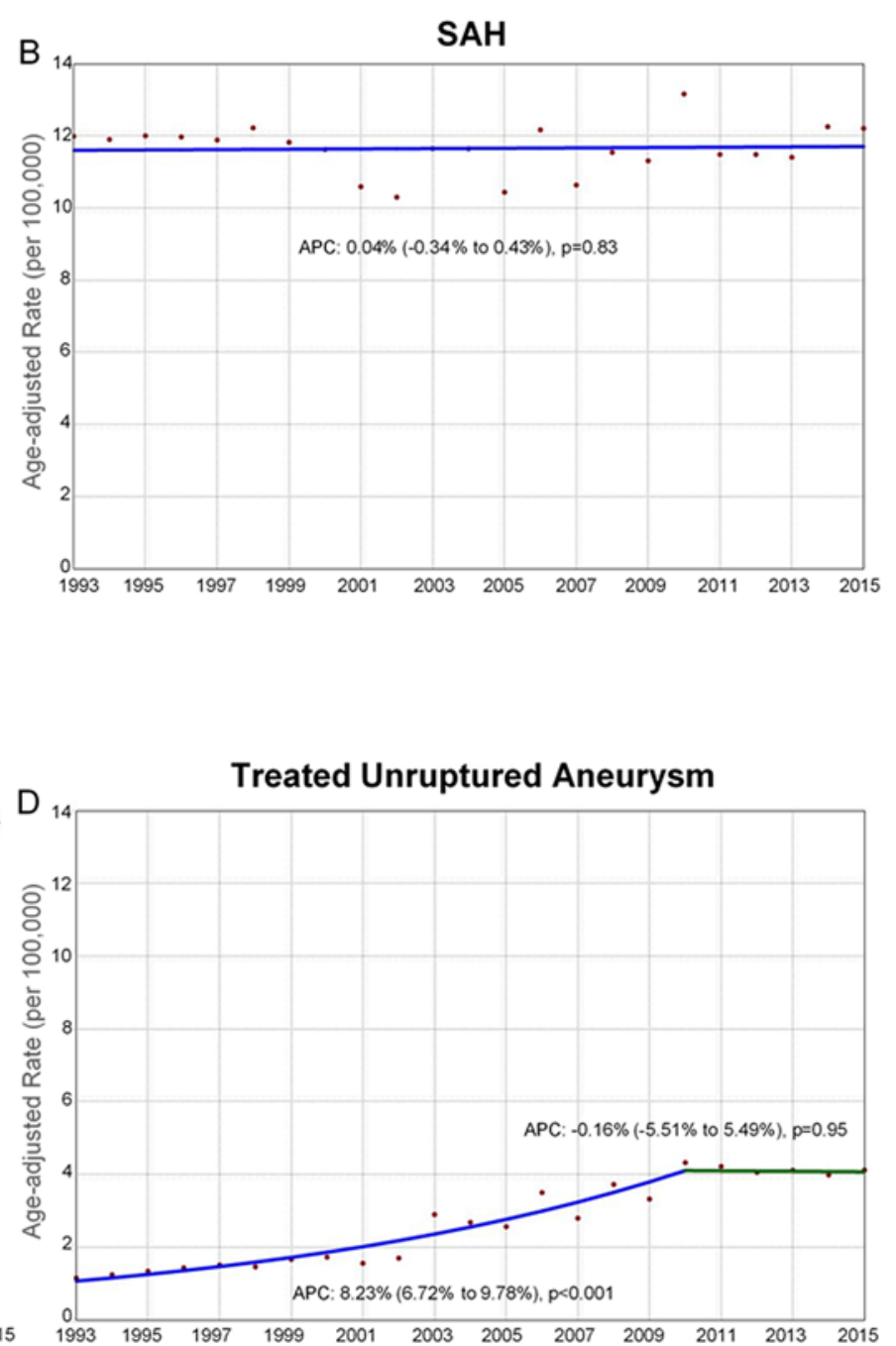

FIG. 3. Age-adjusted annual incidence of diagnosis and treatment of unruptured aneurysm versus SAH (A) and their APCs (B-D), from 1993 to 2015. Figure is available in color online only.

CI $1.83 \%-10.03 \%, \mathrm{p}=0.01$ ) in ruptured aneurysms (Fig. $2 \mathrm{C}$ and $\mathrm{D}$ ). Interestingly, the use of clipping in ruptured aneurysms was steadily declining in the 1990s prior to widespread adoption of EVT or publication of the ISAT. This decline accelerated from 1999 with an APC of $-6.22 \%$ (95\% CI $-7.03 \%$ to $-5.41 \%, \mathrm{p}<0.001)$. In contrast, clipping unruptured aneurysms did not decrease, and indeed the absolute number of admissions with clipping showed a small increase (APC $2.02 \%, 95 \%$ CI $1.05 \%-3.00 \%$, p < 0.001 ) throughout the study period (Fig. 2E and F).

\section{Effect on SAH Incidence}

We examined whether this overall increase in both detection and treatment of unruptured aneurysms over time (by EVT or clipping) affected the overall incidence of aneurysmal SAH in the US during the study period. Figure 3A shows age-standardized incidence trends of admissions for unruptured aneurysms versus incidence of admission for SAH. From 1993 to 2015, we found an increase in the incidence of admissions with diagnosis or treatment of unruptured aneurysms (from 4.1 to 13.7 and from 1.3 to 4.3 per 100,000 persons, respectively). In contrast, we found no change in the incidence of SAH during this time period (from 12.0 to 12.2 per 100,000 persons, range 10.3-13.2). This corresponded with significantly positive APCs for both diagnosis and treatment of unruptured aneurysms during this time, whereas the APC for admission with $\mathrm{SAH}$ remained small and insignificant $(0.04 \%, 95 \% \mathrm{CI}-0.34 \%$ to $0.43 \%, \mathrm{p}=0.83)$ throughout the study period (Fig. 3B-D).

\section{Trends in Outcomes Over Time}

We then examined outcomes of aneurysm treatment during the study period, contrasting routine discharges (e.g., home) with nonroutine discharges (e.g., discharge to short-term hospital, or skilled nursing and other healthcare facilities). Outcomes data for EVT during 1993-1997 proved variable, due to relatively few aneurysms being treated with EVT during this early time period. We therefore compared outcomes from 1998 to 2015. From 1998 


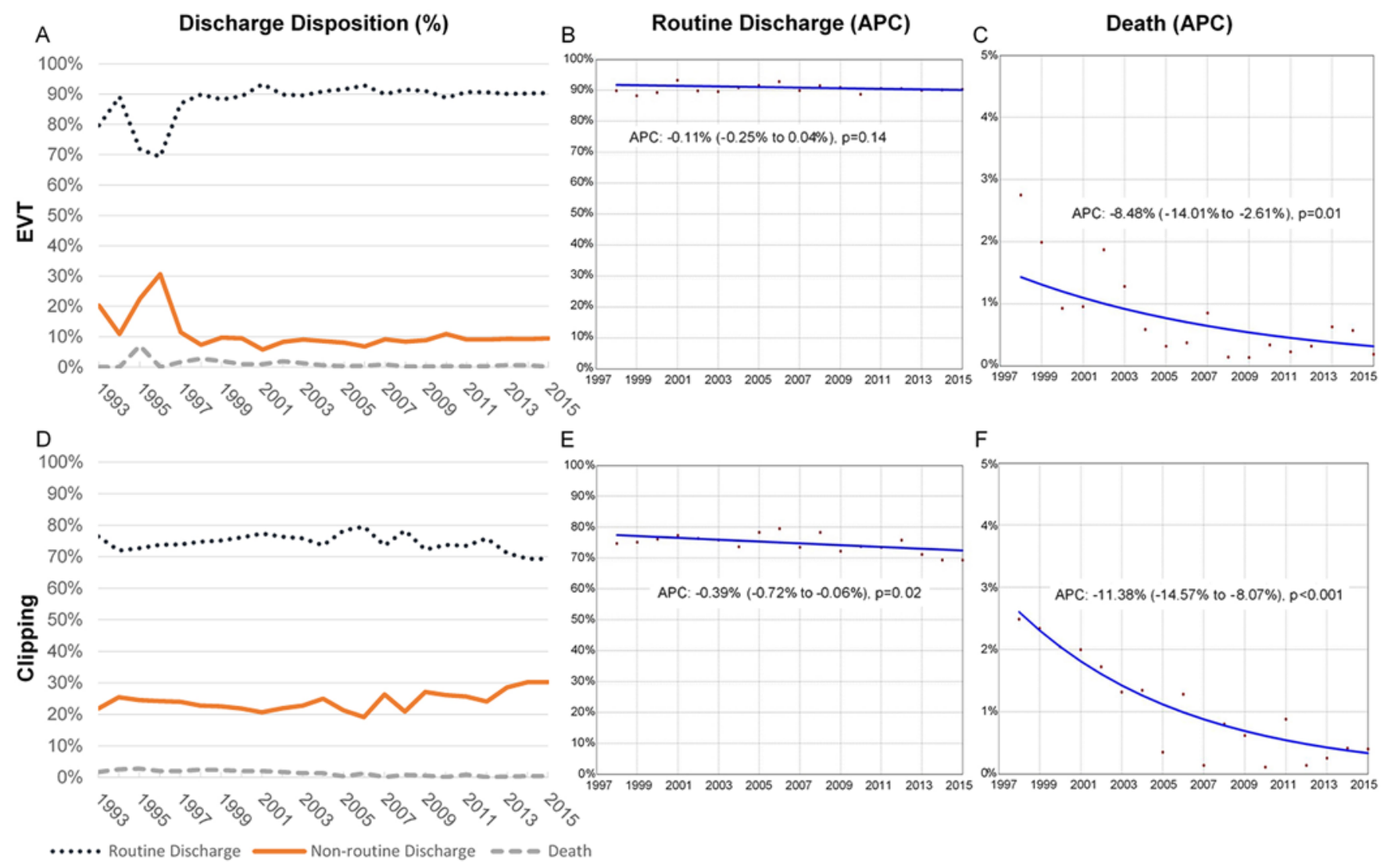

FIG. 4. Discharge disposition percentage (1993-2015) and APC (1998-2015) in patients treated for unruptured aneurysms, EVT $(\mathrm{A}-\mathrm{C})$ versus clipping (D-F). Figure is available in color online only.

onward, patients with unruptured aneurysms experienced significantly fewer routine discharges after clipping versus EVT $(69.3 \%-79.5 \%$ vs $88.3 \%-93.3 \%$, p < 0.001$)$ across all years examined (Fig. 4A and D). Interestingly, there was minimal change over time in the proportion of patients discharged home (Fig. 4B and E) after clipping (APC $-0.39 \%$, $95 \% \mathrm{CI}-0.72 \%$ to $-0.06 \%, \mathrm{p}=0.02$ ) or after EVT (APC $-0.11 \%, 95 \% \mathrm{CI}-0.25 \%$ to $0.04 \%, \mathrm{p}=0.14$ ) of unruptured aneurysms. Mortality was low and improved from first to last epoch studied in both clipping (2.1\% to $0.4 \%$, APC $-11.38 \%, 95 \% \mathrm{CI}-14.57 \%$ to $-8.07 \%, \mathrm{p}<0.001)$ and EVT (1.3\% to $0.5 \%$, APC $-8.48 \%, 95 \%$ CI $-14.01 \%$ to $-2.61 \%$, p $=0.01$ ) over time (Fig. 4A, C, D, and F).

In patients with ruptured aneurysms, routine discharges remained low (30.2\%-49.3\%; Fig. 5A and D) and decreased over time (Fig. 5B and E) in both clipping (APC $-0.85 \%, 95 \% \mathrm{CI}-1.51 \%$ to $-0.18 \%, \mathrm{p}=0.02)$ and EVT (APC $-0.65 \%, 95 \% \mathrm{CI}-1.31 \%$ to $0.03 \%, \mathrm{p}=0.06)$. There was a corresponding increase over time in nonroutine discharges after EVT (APC 1.24\%, 95\% CI 0.79\%-1.69\%, p $<0.001$ ) and clipping (APC $1.10 \%, 95 \%$ CI $0.64 \%-1.55 \%$, $\mathrm{p}<0.001)$. Mortality diminished from the first to last epoch studied after both clipping (13.3\% to $11.8 \%$, APC $-1.44 \%, 95 \% \mathrm{CI}-2.24 \%$ to $-0.63 \%, \mathrm{p}<0.001)$ and EVT (15.8\% to $12.4 \%$, APC $-2.48 \%, 95 \%$ CI $-3.74 \%$ to $-1.20 \%$, $\mathrm{p}<0.001$ ) for ruptured aneurysms (Fig. 5A, C, D, and F). Mortality of untreated SAH patients also declined (APC
$-1.67 \%, 95 \%$ CI $-1.83 \%$ to $-1.52 \%, \mathrm{p}<0.001)$ during the entire study period but remained high overall (range 24.7\%-36.4\%; Supplementary Fig. 1). The cumulative decreases in mortality of both treated and untreated SAH resulted in a decreased mortality in overall SAH from $28.0 \%$ to $22.2 \%$ in $1998-2015$ (Supplementary Fig. 1).

When examining all patients with $\mathrm{SAH}$ in the last epoch, untreated SAH was associated with death or palliative discharge in $21.7 \%$, discharge home in $21.3 \%$, and nonpalliative discharge in $29.4 \%$ (the remaining $27.5 \%$ of patients with SAH underwent clipping or EVT). While the lack of treatment in patients who eventually died or went home might be explained by moribund patient status or nonaneurysmal SAH, respectively, we examined whether SAH severity (NIS-SSS score), comorbidities (ECI), or advanced age ( $\geq 80$ years) might explain the lack of treatment in patients with SAH undergoing nonpalliative discharge. We found significantly higher NIS-SSS score $(4.53,95 \%$ CI $4.43-4.63$ vs $1.68,95 \%$ CI $1.63-1.72$; $p<$ $0.001)$, comorbidity score $(3.32,95 \%$ CI $3.30-3.34$ vs 2.13 , $95 \%$ CI $2.11-2.15 ; \mathrm{p}<0.001$ ), and proportion of octogenarians $(21.8 \%$ vs $7.3 \%, \mathrm{p}<0.001)$ in patients with untreated SAH undergoing nonpalliative discharge versus those going home.

Given the multiple factors (some confounding) that affect outcome after aneurysm treatment, we performed multivariate regression to adjust for various patient and 


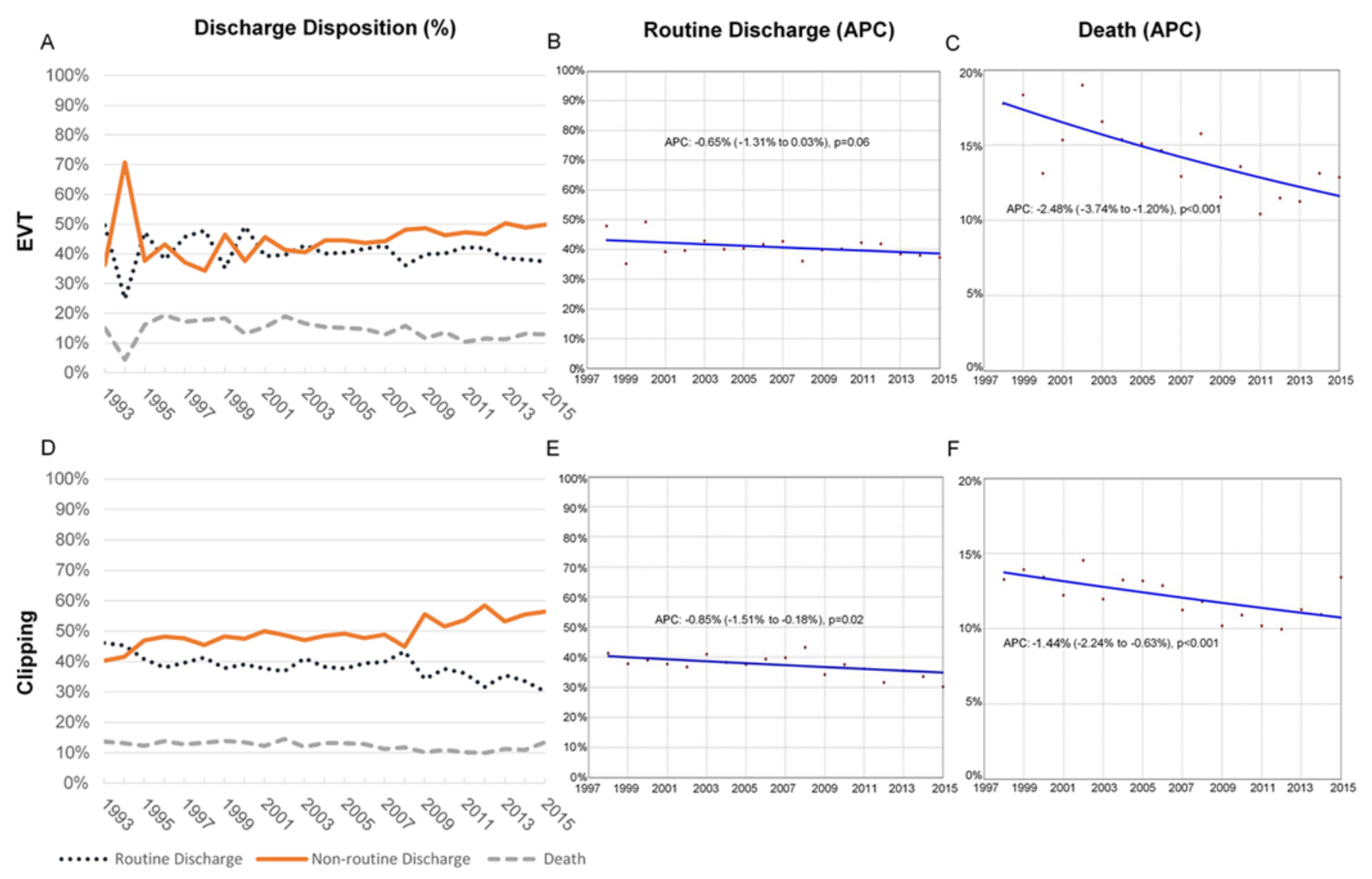

FIG. 5. Discharge disposition percentage (1993-2015) and APC (1998-2015) in patients treated for ruptured aneurysms, EVT $(\mathrm{A}-\mathrm{C})$ versus clipping (D-F). Figure is available in color online only.

hospital characteristics (Supplementary Table 3). EVT remained associated with a significantly higher rate of discharge home as compared to clipping in both unruptured (aRR 1.30, 95\% CI 1.28-1.32, p < 0.001) and ruptured (aRR $1.22,95 \%$ CI 1.18-1.26, p < 0.001) aneurysms.

\section{Trends in Complications and Adverse Events Over Time}

To better understand differential outcomes of clipping versus EVT in unruptured aneurysms, we examined temporal trends in four key adverse events: need for an external ventricular drain (EVD), prolonged endotracheal intubation and mechanical ventilation, and iatrogenic stroke. These adverse events were relatively higher after clipping versus EVT for unruptured aneurysms throughout most of the study period but decreased over time in both modalities (Fig. 6A and C). Of note, the decreasing need for EVD in unruptured aneurysms, which can serve as a surrogate estimate for intraoperative rupture in EVT or complexity and/or complications in clipping, appears to have plateaued in both EVT $(0.1 \%-0.4 \%)$ and clipping (0.8\%-1.5\%) since 2010. In contrast, such adverse events (which, with the exception of iatrogenic stroke, may have been necessary for the SAH patient) were seen more frequently over time in ruptured aneurysms throughout the study period, and with less distinction between clipping and EVT (Fig. 6B and D).
Possible reasons for the observed increase in adverse events over time following treatment of ruptured aneurysms (irrespective of modality) include increasing patient age, comorbidity, and/or SAH severity; all three factors were found to increase in patients presenting with $\mathrm{SAH}$ during the study period (Fig. 7A, C, and E; all p < 0.001). It is unlikely that these increases were due to a temporal change in proportion of aneurysmal versus nonaneurysmal SAH, as the latter (estimated by proportion of SAH patients discharged home without treatment) remained nearly constant (range $20.0 \%-22.1 \%$, APC $0.24 \%$, 95\% CI $-0.05 \%$ to $0.53 \%, p=0.10$ ). We also found similar increases in patient age, comorbidity, and SAH severity (all $\mathrm{p}<0.001$ ) in the subgroup of patients with SAH who underwent treatment for their ruptured aneurysm (Fig. 7B, D, and F); this was not explained by a potential selection bias toward including more older or sicker patients for treatment over time as the proportion of patients treated for SAH between 1993 and 2015 showed no such temporal trend (range 26.5\%-34.2\%, Fig. 1B).

Finally, to better quantify overall trends over time with respect to complications, adverse events, and outcomes, we looked at three key epochs within the study time period by averaging 3 years of data from the beginning of the study (1999-2001), 3 years of data after the publication of the ISAT (2003-2005), and finally 3 years of data at the 


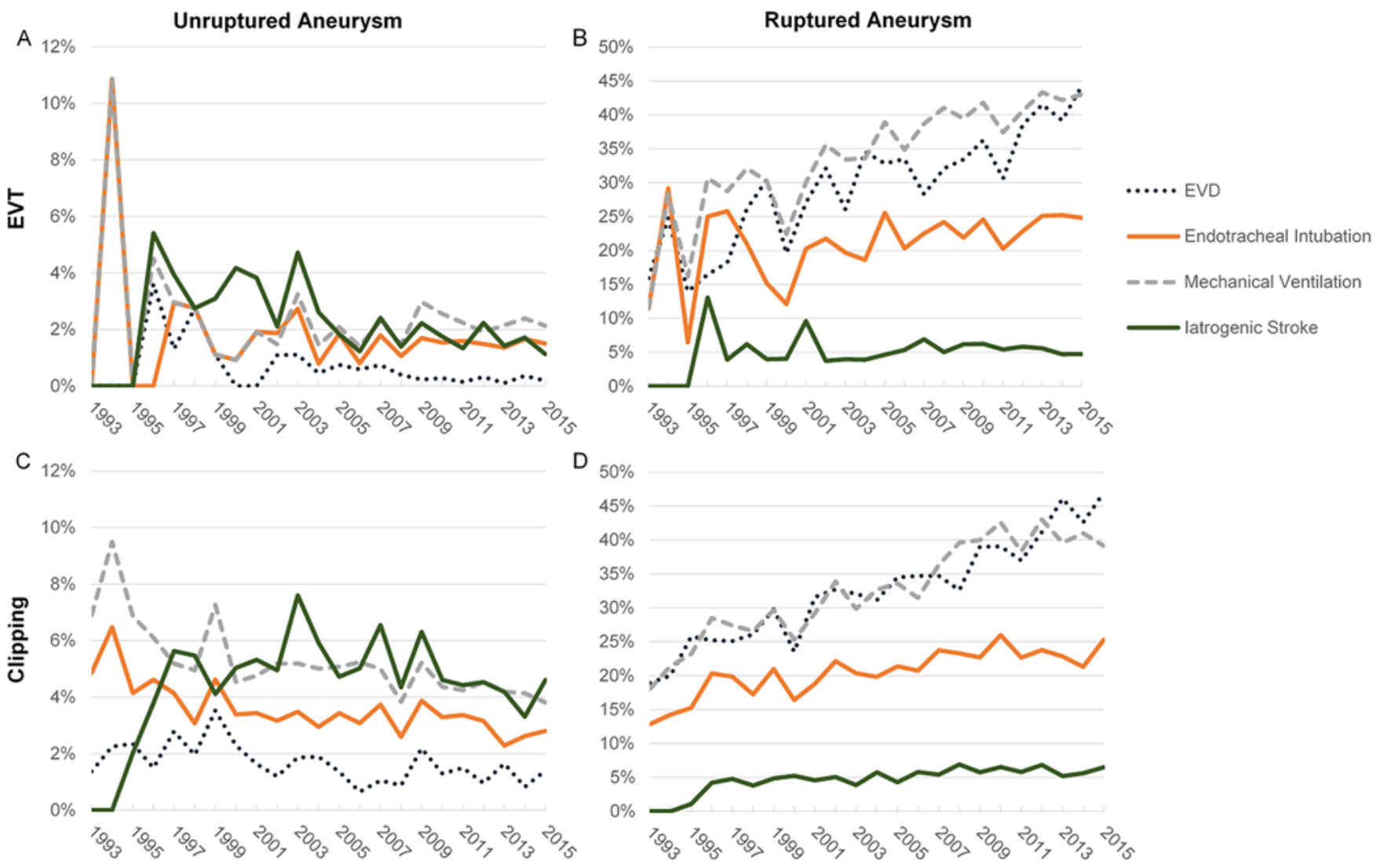

FIG. 6. Complications and adverse events in patients treated for unruptured and ruptured aneurysms, EVT (A and B) versus clipping (C and D), from 1993 to 2015. Figure is available in color online only.

end of the study period (2013-2015). We found significant differences in the risk of complications and death/nonroutine discharge that favored EVT rather than clipping in the treatment of unruptured aneurysms in all three epochs, although these differences narrowed over time. In contrast, this differential risk was much less apparent in ruptured aneurysms, particularly in the most recent epoch (Fig. 8).

\section{Discussion}

We analyzed volumes, outcomes, and complications of aneurysm treatment in the US over nearly 2.5 decades (1993-2015), using the NIS to provide the best available representation of general practice patterns over this time period. To our knowledge, this is the longest time period assessed using the NIS, with revised methodology permitting uniform assessment of volume and outcome trends over the entire study period. Accordingly, from 1993 to 2015, we found no significant trend in the age-adjusted annual incidence of overall spontaneous SAH (10.3-13.2 per 100,000 persons) or the proportion that proved nonaneurysmal (20.0\%-22.1\%, estimated by discharges home without aneurysm treatment). SAH led to treatment in only one-third of patients, well within the $29.0 \%-32.4 \%$ range found across several prior (shorter-term) published analyses using the NIS ${ }^{30,36}$ or state hospital discharge databases. ${ }^{4,9}$ The rational for not offering treatment in the re- maining SAH patients was estimated to be nonaneurysmal causes (21.3\% discharged home), moribund status (21.7\% died or palliatively discharged), or a combination of advanced age, SAH severity, and comorbidities in the $29.4 \%$ with nonroutine discharges when examining the last epoch of the study period. Overall mortality from SAH decreased from $28.0 \%$ to $22.2 \%$ in 1998-2015; mortality after treatment of ruptured aneurysms similarly diminished in both EVT (17.7\% to 12.9\%; Fig 5A) and clipping (13.7\% to $13.4 \%$; Fig. 5D), becoming indistinguishable between the two modalities in the last epoch studied (2013-2015). Our evaluation of SAH incidence and survival is within the range of older literature and provides the most up-todate estimates for the US population. ${ }^{24}$

We found a marked increase in EVT for both ruptured and unruptured aneurysms after the ISAT ${ }^{26}$ and ISUIA ${ }^{45}$ reported better outcomes for EVT versus microsurgical clipping (Fig. 1), consistent with prior analyses of shorter time periods in the NIS., ${ }^{3,22,31}$ However, the longer length of our study period highlights several interesting trends: 1) clipping ruptured aneurysms has been consistently decreasing across the study period, before and after the ISAT; 2) clipping unruptured aneurysms has gradually increased irrespective of the ISUIA; and 3) EVT for unruptured aneurysms continues to increase unabated at $7.2 \%$ per year since 2004. These trends run contrary to the presumption that the decrease in clipping ruptured aneurysms began 
SAH

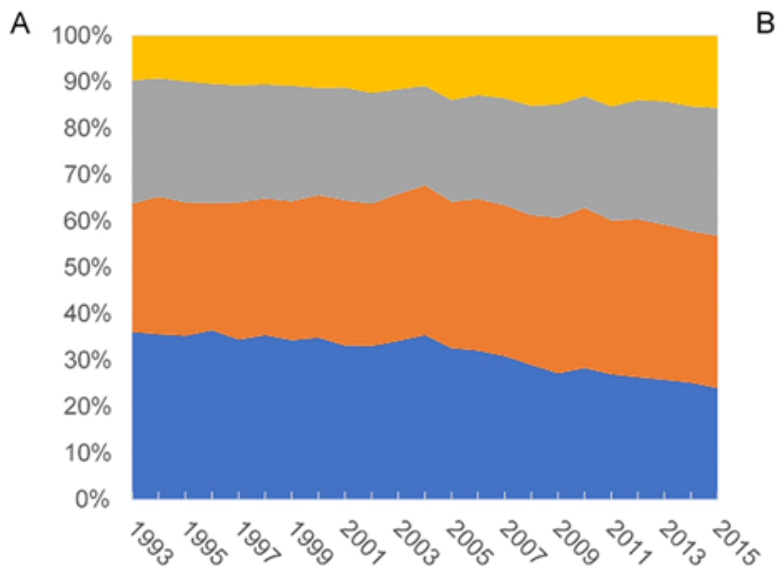

C

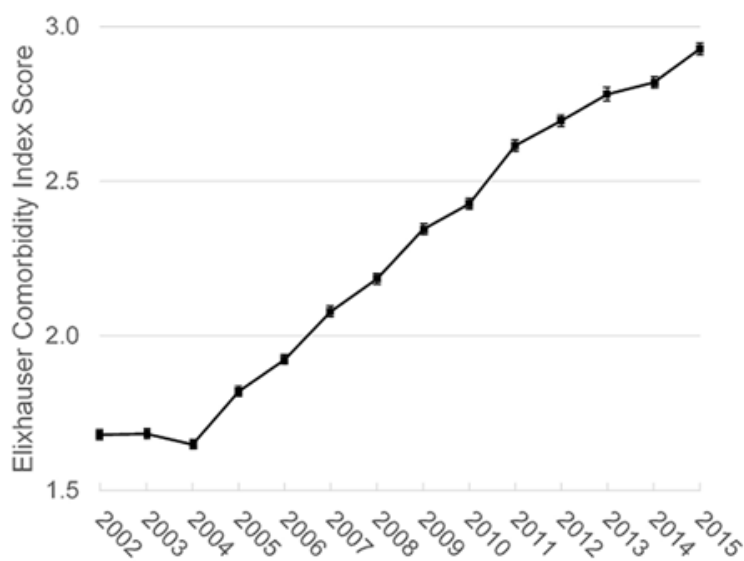

$\mathrm{E}$

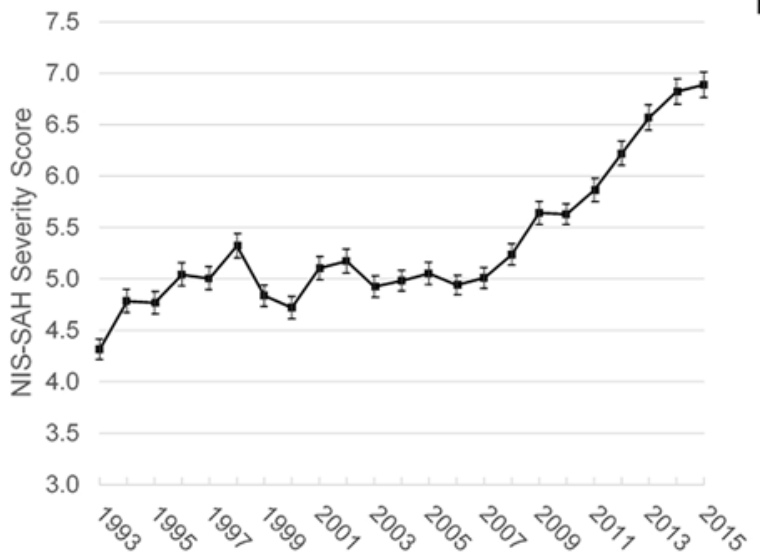

Treated Ruptured Aneurysm

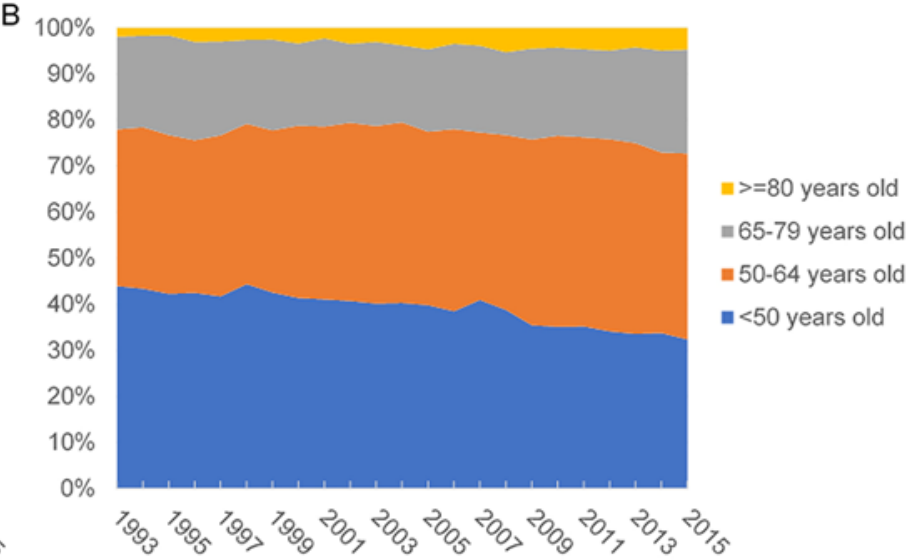

D

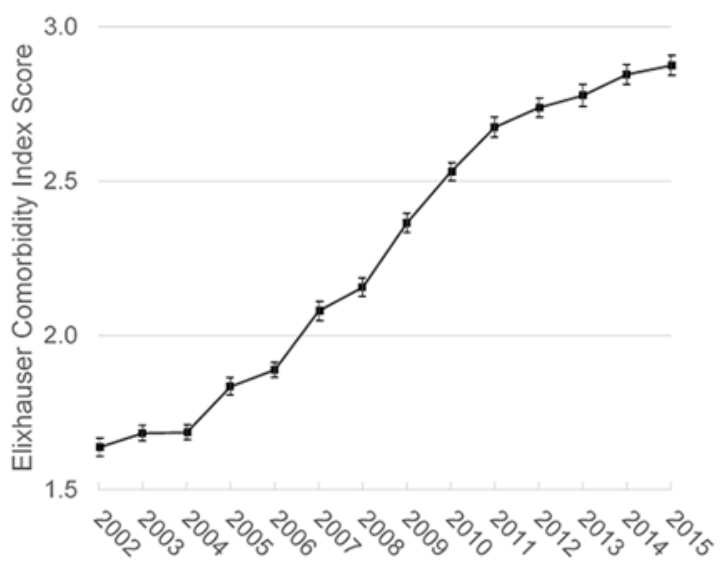

$\mathrm{F}$

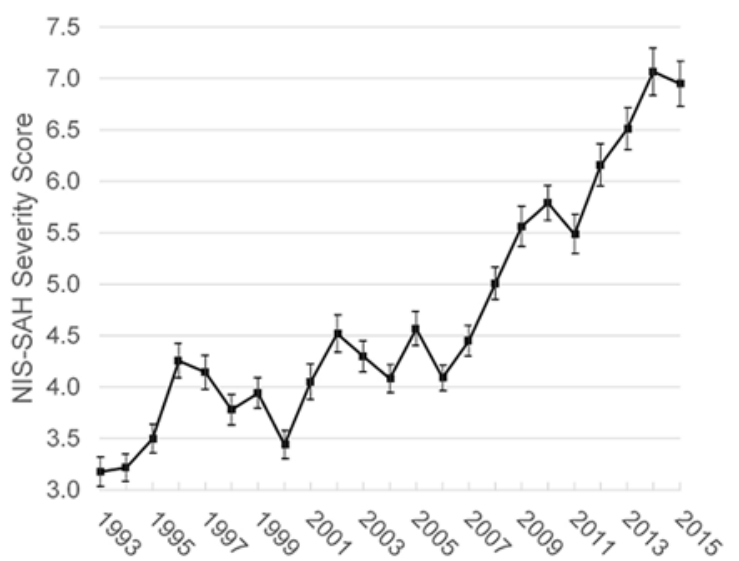

FIG. 7. Trends in age groups (1993-2015), comorbidity score (2002-2015), and NIS-SSS (1993-2015) in all patients with SAH (A, $\mathrm{C}$, and $\mathrm{E}$ ) and in patients with $\mathrm{SAH}$ undergoing aneurysm treatment (B, D, and F). Figure is available in color online only.

after publication of the ISAT, and raise questions about the observed steady increase in treatment of unruptured aneurysms (by clip or EVT) despite publication of the ISUIA and other publications suggesting a favorable natural history for smaller unruptured aneurysms. ${ }^{27,44,45}$

\section{Impact on SAH}

The marked increase in diagnosis and treatment of unruptured aneurysms over the past decades could be expected to reduce the overall incidence of SAH. We found that at the population level, the age-adjusted annual incidence of aneurysm diagnosis and treatment in the US both tripled from 1993 to 2015, without any appreciable trend toward a decrease in the annual incidence of SAH. Our finding of no overall change in SAH incidence in the US from 1993 to 2015 is consistent with a recent meta-analysis 


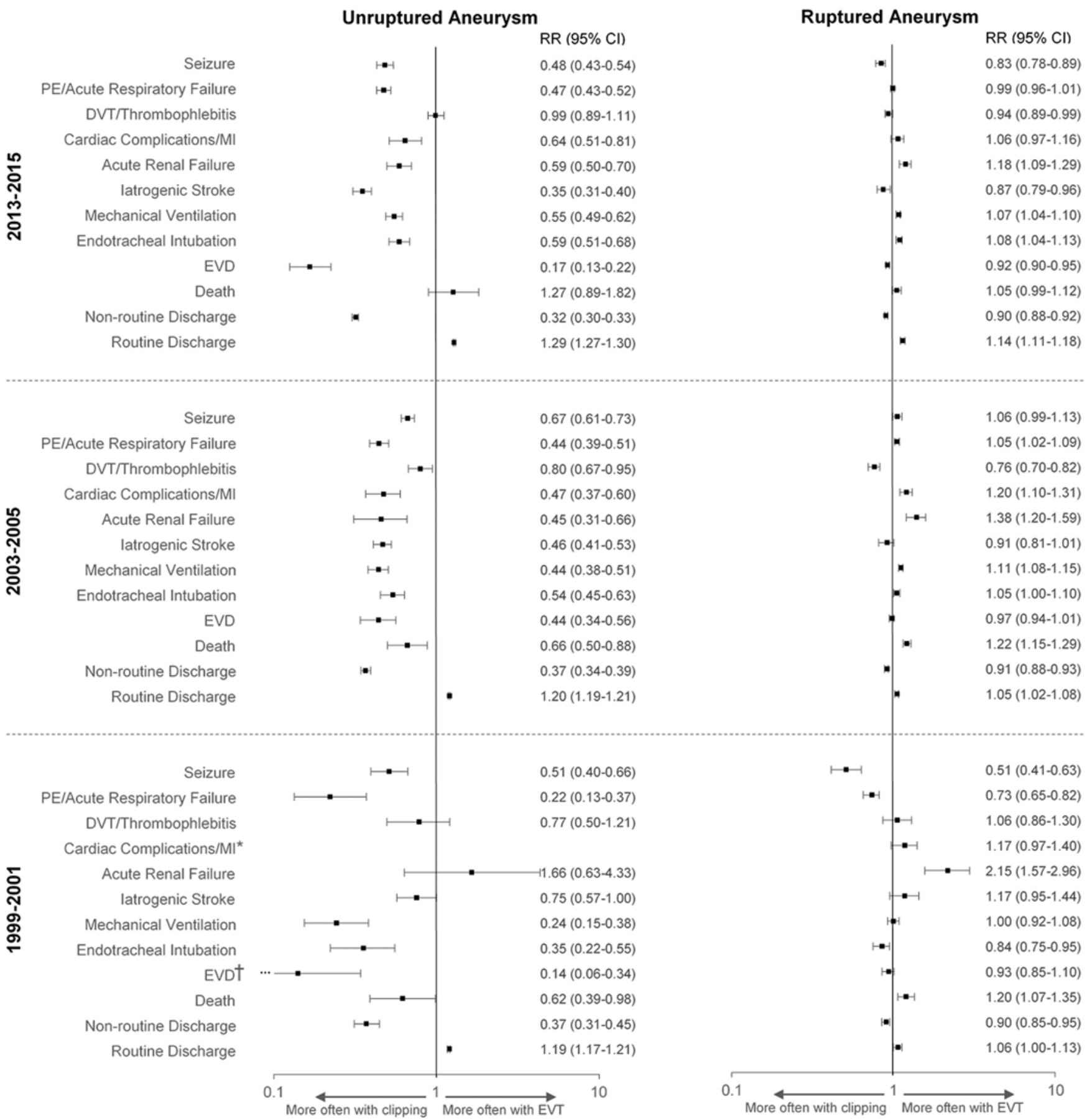

FIG. 8. Risk ratio (log scale) of discharge disposition, complications, and adverse events in EVT versus clipping in patients with unruptured and ruptured aneurysms over three epochs. * The frequency of cardiac complications/MI in patients with unruptured aneurysm with EVT was 0 during the 1999-2001 time period, therefore an RR could not be estimated. $†$ The lower bound of the confidence interval for EVD is truncated in order to fit the graph. DVT = deep vein thrombosis; $\mathrm{MI}=$ myocardial infarction; $\mathrm{PE}=$ pulmonary embolism.

of global SAH showing a decrement of only $14 \%$ in North America between 1980 and 2010 (in contrast to more than $40 \%$ in Europe and Asia during the same time period). ${ }^{11}$ This may imply that current algorithms for patient selection in the treatment of unruptured aneurysms in the US (typically based on aneurysm size, shape, and location; perceived perioperative complication rates; and patient age and preferences) are inadequate to determine which unruptured aneurysms harbor a higher lifetime risk of rupture. A recent Norwegian nationwide case-control study simi- 
larly found traditional aneurysm morphology parameters could not predict rupture risk. ${ }^{37}$ Ruptured and unruptured aneurysms may therefore represent different populations and/or have different pathogeneses,,$^{15}$ with SAH resulting from aneurysms that rupture a short time after formation, leaving little time for detection and treatment while unruptured. ${ }^{20,46}$ This may explain the discrepancy between the observation that most aneurysms presenting with rupture are small $(<7 \mathrm{~mm})$, whereas similarly sized unruptured aneurysms appear to have a low risk of rupture. ${ }^{32}$ Indeed, some have suggested that optimal treatment of incidental unruptured aneurysms $\leq 3 \mathrm{~mm}$ in size may simply be to ignore them. ${ }^{25}$ Finally, modifiable risk factors such as hypertension and smoking may be much more impactful on overall SAH burden than treating unruptured aneurysms, ${ }^{11}$ with the population-attributable risks of alcohol consumption, smoking, and hypertension accounting for $11 \%-21 \%$, $20 \%$, and $17 \%$ of SAH, respectively. ${ }^{34}$

Interestingly, after the initially large increase seen in annual diagnosis of unruptured cerebral aneurysms (attributed to widespread availability and increased utilization of noninvasive neurovascular imaging techniques), ${ }^{40}$ the pace of growth in diagnosis and treatment of unruptured aneurysms has slowed. This suggests that further increased diagnosis and/or screening of unruptured aneurysms is unlikely to occur, and therefore unlikely to help reduce $\mathrm{SAH}$ (especially given little change in the incidence of SAH thus far). Improved biomarkers of rupture risk such as vessel-wall imaging ${ }^{23}$ may therefore be necessary to better triage the management of unruptured aneurysms toward initial serial observation versus upfront treatment.

\section{Impact on Training and Practice}

These trends in practice volume have significant implications for trainees. For example, while there has been little change in the number of unruptured aneurysms treated surgically, there has been a nearly 3 -fold reduction in surgical treatment of ruptured aneurysms between 1993 and 2015. Thus, while neurosurgical resident training may benefit from a largely unchanged number of learning opportunities for clipping unruptured aneurysms, standard residency training may not provide competency in clipping ruptured aneurysms. This may be further exacerbated by case dispersion across an increased number of residency training positions and/or across centers that may not harbor residency training programs. ${ }^{29}$

Similar implications exist for neurointerventionalists (NIs). In the early 2010s there were an estimated 800 NIs practicing in the US, and another estimated 40-80 NI fellows graduating each year. ${ }^{12,47}$ According to data obtained from the websites of the Society of Neurointerventional Surgery, ${ }^{38}$ the Society of Vascular and Interventional Neurology, ${ }^{39}$ the American Association of Neurological Surgeons, ${ }^{2}$ and the American Academy of Neurology, ${ }^{1}$ the estimated number of fellows graduating is now up to nearly 80-90 per year, maintaining a steady if not increasing slope for the number of NIs entering practice per year. While debate exists regarding the need for additional NIs to address the increasing need for stroke thrombectomy and call coverage, $, 12,33,47$ it is important to note that this increase in the NI workforce largely occurred prior to publication of the seminal thrombectomy trials in 2014$2015,5,7,13,19,35$ and this growth in the NI workforce may itself have played a role in the marked increase in EVT for unruptured aneurysms. Given that diagnosis and treatment of unruptured aneurysms has slowed (and diagnosis of SAH remains unchanged), this continued increase in the NI workforce will inevitably lead to fewer aneurysm treatment opportunities per practitioner, raising inevitable questions regarding practitioner competence and comfort in treating these lesions. To date, aneurysm volume requirements have only been applied at the institutional rather than individual level ${ }^{18}$ and at levels (15 clipping or EVT procedures) below what is considered a high-volume center $(>60)$ that would be associated with better outcomes. ${ }^{42}$ This is in contrast to recent mandates requiring a minimum of 15 thrombectomies per year per practitioner taking call at a Joint Commission-accredited CSC, ${ }^{18}$ and may portend the eventual imposition of individual volume thresholds for aneurysm treatment as well among NIs.

\section{Impact on Rates of Complications and Adverse Events}

Changes in volume and practice data are known to correlate with complication rates and outcomes. ${ }^{17,42} \mathrm{We}$ found trends over time toward decreasing complications in the treatment of unruptured aneurysms, in contrast to increasing adverse events following treatment of ruptured aneurysms. The latter corresponded with temporal increases in severity, age, and comorbidity in all patients with $\mathrm{SAH}$, as well as in those selected for treatment. This was not accounted for by any discernable change in the proportion of patients with SAH selected for treatment, or the estimated proportion of SAH patients with aneurysmal versus nonaneurysmal etiology.

EVT demonstrated fewer complications and adverse events than clipping at nearly all time points, although this became less apparent over time, especially in ruptured aneurysms. The less apparent difference in adverse events between EVT and clipping in ruptured aneurysms, while seemingly counterintuitive to the results of the ISAT, may simply be due to the overwhelmingly devastating nature of SAH when measured at a population level (rather than within the narrow context of a randomized trial). Alternatively, clinical teams may have grown more experienced in choosing whether clipping or EVT is more appropriate for specific aneurysm size, morphology, and location, leading to narrowing of margins of difference in outcomes across the two modalities over time. Finally, the diminishing risk differential between clipping and EVT over time could be due to practitioners using advances in EVT to treat aneurysms with higher complexity or risk, and/or practitioners selecting lower-risk patients for clipping. While the NIS does not provide a method to estimate the latter, the need for EVD (a surrogate for intraoperative rupture, complexity, and/or complications) after treatment of unruptured aneurysms slightly decreased over time and appears to have largely plateaued since 2010 .

\section{Impact on Outcomes}

Despite the highlighted shifts in treatment modality and trends in complication rates during the study period, our analysis does not show marked changes in outcomes 
over this time period. For example, despite significant improvements in mortality, only approximately $90 \%$ of EVT and $70 \%-80 \%$ of surgically treated unruptured aneurysm patients have been discharged home after treatment every year since 1998; this proportion has never exceeded $50 \%$ in ruptured aneurysm patients and has continued to decrease during the study period. In other words, patients being treated for an unruptured aneurysm have an approximately 1 out of 4 chance of not going home after clipping versus 1 out of 10 after EVT; this becomes less than 1 out of 2 if the aneurysm is ruptured. It is nevertheless possible that improvements in SAH outcome could be masked by recent workflow changes due to hospital stroke accreditation that trigger protocolized rehabilitation assessments leading to discharge to rehabilitation facilities rather than home. But this is less likely in unruptured aneurysms given the relatively flat trends in their outcomes over 2 decades and the fact that such patients are typically not considered "stroke" patients. Additionally, our data show a higher real-world complication rate when treating unruptured aneurysms than seen in contemporaneous published trials and case series, with a recent large meta-analyses of EVT for unruptured aneurysms reporting a combined procedural mortality and morbidity of only $3.1 \%$ since $2004 .^{28}$ Possible explanations for this discrepancy may be that advances in devices, techniques, and neurocritical care have resulted in changes that are either too small to measure (unlikely given the statistical power of NIS) or are less reflected in the general US population (as measured by NIS) versus more selective case series and meta-analyses. ${ }^{28}$

Finally, while results of the ISAT and ISUIA may predict continued divergence in the superiority of EVT over clipping, temporal trends in the NIS suggest the opposite. This may reflect better selection of aneurysms for each modality. Additionally, with new and improved endovascular technology, the ability to treat more complex and high-risk lesions may blur the initial advantage of EVT in the ISAT as applied to more selected and/or simpler lesions. It should therefore be emphasized that this observational, real-world data primarily reflects changes in patient selection and practice over 2 decades, rather than results of a randomized trial. However, our analysis suggests that today's patients with SAH can expect largely similar outcomes from EVT or clipping following recommendations from a team experienced in both modalities.

\section{Limitations}

Our data and analysis have several limitations. In particular, the NIS is a retrospective administrative database without the granularity required to fully assess the complexity of aneurysm treatment. However, it is likely to be a better representation of real-world practice than randomized trials (which typically enroll highly selected centers and patients) or registries and selected case series that are subject to publication bias. The NIS database only provides inpatient outcomes, and thus 30- and 90-day outcomes could not be assessed in our analysis, nor could we account for patients who died before admission to the hospital or before diagnosis of SAH. Similarly, the NIS database is based on discharge data and cannot distinguish between readmissions, meaning that some of the increased diagnoses of unruptured aneurysms may be due to readmission of previously diagnosed aneurysms. Methodological differences between this paper and several other NISbased studies may prevent direct comparison of our results with prior work, including 1) utilizing all (rather than only primary) diagnosis fields for SAH/brain aneurysms, and 2) grouping outcomes due to lack of detailed discharge disposition across most of the study period, which limited our ability to separate discharges to acute rehabilitation from discharges to other facilities such as hospice or skilled nursing care. The latter grouping, while necessary, may have impacted our results and masked changes in clinical outcomes. Our analysis does not include data from 2016 (currently the last year available) onward due to changes in NIS methodology, which limits our ability to assess the impact of newer iterations of endovascular devices such as low-profile intracranial stents and intrasaccular flow diverters. Finally, we were unable to examine the effect of neurosurgical training programs because the NIS does not provide data regarding the existence of a neurosurgical and/or endovascular training program at each site (irrespective of teaching hospital status).

\section{Conclusions}

Analysis of temporal trends in aneurysm treatment in the US from 1993 to 2015 finds clipping steadily decreasing for ruptured aneurysms and slightly increasing in unruptured aneurysms throughout the study period, whereas EVT markedly increased (in both ruptured and unruptured aneurysms) after publication of the ISAT. The increased diagnosis and treatment of unruptured aneurysms has not affected the annual incidence of SAH. However, patients with SAH are increasingly older, harbor more comorbidities, and have more severe $\mathrm{SAH}$, thus treatment of these patients is associated with increasing adverse events over time. EVT had fewer complications than clipping in unruptured aneurysms but this was less apparent in ruptured aneurysms, with the margin of difference diminishing over time. The proportion of discharges home after treatment of unruptured aneurysms has minimally decreased after 1998 and is less frequent than that reported in case series or randomized trials. These data have significant implications for training, certification, and selection of patients for aneurysm treatment.

\section{References}

1. American Academy of Neurology (AAN): Directory for Fellowship Positions. Minneapolis: AAN (https://www.aan. com/Fellowship) [Accessed December 16, 2019]

2. American Association of Neurological Surgeons (AANS): Neurosurgical Fellowship Training Program Directory. Rolling Meadows, IL: AANS (http://www.aans.org/Trainees/ Academic-Fellowship-Directory) [Accessed December 16, 2019]

3. Andaluz N, Zuccarello M: Recent trends in the treatment of cerebral aneurysms: analysis of a nationwide inpatient database. J Neurosurg 108:1163-1169, 2008

4. Bardach NS, Zhao S, Gress DR, Lawton MT, Johnston SC: Association between subarachnoid hemorrhage outcomes and number of cases treated at California hospitals. Stroke 33:1851-1856, 2002

5. Berkhemer OA, Fransen PS, Beumer D, van den Berg 
LA, Lingsma HF, Yoo AJ, et al: A randomized trial of intraarterial treatment for acute ischemic stroke. N Engl J Med 372:11-20, 2015

6. Brinjikji W, Rabinstein AA, Lanzino G, Kallmes DF, Cloft HJ: Effect of age on outcomes of treatment of unruptured cerebral aneurysms: a study of the National Inpatient Sample 2001-2008. Stroke 42:1320-1324, 2011

7. Campbell BC, Mitchell PJ, Kleinig TJ, Dewey HM, Churilov L, Yassi N, et al: Endovascular therapy for ischemic stroke with perfusion-imaging selection. N Engl J Med 372:1009_ 1018, 2015

8. Cloft H: Workforce needs for endovascular acute ischemic stroke therapy: myth or reality? Neurosurg Focus 36(1):E8, 2014

9. Cross DT III, Tirschwell DL, Clark MA, Tuden D, Derdeyn $\mathrm{CP}$, Moran CJ, et al: Mortality rates after subarachnoid hemorrhage: variations according to hospital case volume in 18 states. J Neurosurg 99:810-817, 2003

10. Elixhauser A, Steiner C, Harris DR, Coffey RM:

Comorbidity measures for use with administrative data. Med Care 36:8-27, 1998

11. Etminan N, Chang HS, Hackenberg K, de Rooij NK, Vergouwen MDI, Rinkel GJE, et al: Worldwide incidence of aneurysmal subarachnoid hemorrhage according to region, time period, blood pressure, and smoking prevalence in the population: a systematic review and meta-analysis. JAMA Neurol 76:588-597, 2019

12. Fiorella D, Hirsch JA, Woo HH, Rasmussen PA, Shazam Hussain M, Hui FK, et al: Should neurointerventional fellowship training be suspended indefinitely? J Neurointerv Surg 4:315-318, 2012

13. Goyal M, Demchuk AM, Menon BK, Eesa M, Rempel JL, Thornton J, et al: Randomized assessment of rapid endovascular treatment of ischemic stroke. N Engl J Med 372:1019-1030, 2015

14. Healthcare Cost and Utilization Project (HCUP): HCUP NIS Description of Data Elements. Rockville, MD: Agency for Healthcare Research and Quality (https://www.hcup-us.ahrq. gov/db/vars/dxn/nisnote.jsp) [Accessed December 16, 2019]

15. Hostettler IC, Alg VS, Shahi N, Jichi F, Bonner S, Walsh D, et al: Characteristics of unruptured compared to ruptured intracranial aneurysms: a multicenter case-control study. Neurosurgery 83:43-52, 2018

16. Houchens RLRD, Elixhauser A: Using the HCUP National Inpatient Sample to Estimate Trends. HCUP Methods Series Report \#2006-05. Rockville, MD: Agency for Healthcare Research and Quality (http://www.hcup-us.ahrq. gov/reports/methods/methods.jsp) [Accessed December 16, 2019]

17. Jabbarli R, Wrede KH, Pierscianek D, Dammann P, El Hindy N, Özkan N, et al: Outcome after clipping of unruptured intracranial aneurysms depends on caseload. World Neurosurg 89:666-671.e1, 2016

18. The Joint Commission: Certification Comprehensive Stroke Center. Washington, DC: The Joint Commission (https://www.jointcommission.org/certification/advanced_ certification_comprehensive_stroke_centers.aspx) [Accessed December 16, 2019]

19. Jovin TG, Chamorro A, Cobo E, de Miquel MA, Molina CA, Rovira A, et al: Thrombectomy within 8 hours after symptom onset in ischemic stroke. N Engl J Med 372:2296-2306, 2015

20. Kataoka K, Taneda M, Asai T, Yamada Y: Difference in nature of ruptured and unruptured cerebral aneurysms. Lancet 355:203, 2000

21. Kim HJ, Fay MP, Feuer EJ, Midthune DN: Permutation tests for joinpoint regression with applications to cancer rates. Stat Med 19:335-351, 2000

22. Lin N, Cahill KS, Frerichs KU, Friedlander RM, Claus EB:
Treatment of ruptured and unruptured cerebral aneurysms in the USA: a paradigm shift. J Neurointerv Surg 4:182-189, 2012

23. Lv N, Karmonik C, Chen S, Wang X, Fang Y, Huang Q, et al: Relationship between aneurysm wall enhancement in vessel wall magnetic resonance imaging and rupture risk of unruptured intracranial aneurysms. Neurosurgery 84:E385E391, 2019

24. Macdonald RL, Schweizer TA: Spontaneous subarachnoid haemorrhage. Lancet 389:655-666, 2017

25. Malhotra A, Wu X, Forman HP, Matouk CC, Gandhi D, Sanelli P: Management of tiny unruptured intracranial aneurysms: a comparative effectiveness analysis. JAMA Neurol 75:27-34, 2018

26. Molyneux A, Kerr R, Stratton I, Sandercock P, Clarke M, Shrimpton J, et al: International Subarachnoid Aneurysm Trial (ISAT) of neurosurgical clipping versus endovascular coiling in 2143 patients with ruptured intracranial aneurysms: a randomised trial. Lancet 360:1267-1274, 2002

27. Morita A, Kirino T, Hashi K, Aoki N, Fukuhara S, Hashimoto N, et al: The natural course of unruptured cerebral aneurysms in a Japanese cohort. N Engl J Med 366:2474-2482, 2012

28. Naggara ON, Lecler A, Oppenheim C, Meder JF, Raymond $\mathrm{J}$ : Endovascular treatment of intracranial unruptured aneurysms: a systematic review of the literature on safety with emphasis on subgroup analyses. Radiology 263:828835, 2012

29. Piazza M, Nayak N, Ali Z, Heuer G, Sanborn M, Stein S, et al: Trends in resident operative teaching opportunities for treatment of intracranial aneurysms. World Neurosurg 103:194-200, 2017

30. Qureshi AI, Suri MF, Nasar A, Kirmani JF, Divani AA, $\mathrm{He} \mathrm{W}$, et al: Trends in hospitalization and mortality for subarachnoid hemorrhage and unruptured aneurysms in the United States. Neurosurgery 57:1-8, 2005

31. Qureshi AI, Vazquez G, Tariq N, Suri MF, Lakshminarayan K, Lanzino G: Impact of International Subarachnoid Aneurysm Trial results on treatment of ruptured intracranial aneurysms in the United States. Clinical article. J Neurosurg 114:834-841, 2011

32. Rahman M, Ogilvy CS, Zipfel GJ, Derdeyn CP, Siddiqui $\mathrm{AH}$, Bulsara KR, et al: Unruptured cerebral aneurysms do not shrink when they rupture: multicenter collaborative aneurysm study group. Neurosurgery 68:155-161, 2011

33. Rosman J, Slane S, Dery B, Vogelbaum MA, Cohen-Gadol AA, Couldwell WT: Is there a shortage of neurosurgeons in the United States? Neurosurgery 73:354-355, 365-366, 2013

34. Ruigrok YM, Buskens E, Rinkel GJ: Attributable risk of common and rare determinants of subarachnoid hemorrhage. Stroke 32:1173-1175, 2001

35. Saver JL, Goyal M, Bonafe A, Diener HC, Levy EI, Pereira VM, et al: Stent-retriever thrombectomy after intravenous t-PA vs. t-PA alone in stroke. N Engl J Med 372:2285-2295, 2015

36. Shea AM, Reed SD, Curtis LH, Alexander MJ, Villani JJ, Schulman KA: Characteristics of nontraumatic subarachnoid hemorrhage in the United States in 2003. Neurosurgery 61:1131-1138, 2007

37. Skodvin TO, Evju Ø, Sorteberg A, Isaksen JG: Prerupture intracranial aneurysm morphology in predicting risk of rupture: a matched case-control study. Neurosurgery 84:132-140, 2019

38. Society of Neurointerventional Surgery (SNIS): Fellowship Programs. Fairfax, VA: SNIS (http://snisonline.org/ fellowship-programs/) [Accessed December 16, 2019]

39. Society of Vascular and Interventional Neurology (SVIN): Fellowship Training Programs. Minneapolis: SVIN 
(https://www.svin.org/i4a/pages/index.cfm?pageid=3298) [Accessed December 16, 2019]

40. Thompson BG, Brown RD Jr, Amin-Hanjani S, Broderick JP, Cockroft KM, Connolly ES Jr, et al: Guidelines for the management of patients with unruptured intracranial aneurysms: a guideline for healthcare professionals from the American Heart Association/American Stroke Association. Stroke 46:2368-2400, 2015

41. US Census Bureau: Population and Housing Unit Estimates Datasets. Washington, DC: US Census Bureau (https://www.census.gov/programs-surveys/popest/data/datasets.All.html) [Accessed December 16, 2019]

42. Vespa P, Diringer MN: High-volume centers. Neurocrit Care 15:369-372, 2011

43. Washington CW, Derdeyn CP, Dacey RG Jr, Dhar R, Zipfel GJ: Analysis of subarachnoid hemorrhage using the Nationwide Inpatient Sample: the NIS-SAH Severity Score and Outcome Measure. J Neurosurg 121:482-489, 2014

44. Wermer MJ, van der Schaaf IC, Algra A, Rinkel GJ: Risk of rupture of unruptured intracranial aneurysms in relation to patient and aneurysm characteristics: an updated metaanalysis. Stroke 38:1404-1410, 2007

45. Wiebers DO, Whisnant JP, Huston J III, Meissner I, Brown RD Jr, Piepgras DG, et al: Unruptured intracranial aneurysms: natural history, clinical outcome, and risks of surgical and endovascular treatment. Lancet 362:103-110, 2003

46. Wiebers DO, Whisnant JP, Sundt TM Jr, O'Fallon WM: The significance of unruptured intracranial saccular aneurysms. J Neurosurg 66:23-29, 1987

47. Zaidat OO, Lazzaro M, McGinley E, Edgell RC, Nguyen T, Linfante I, et al: Demand-supply of neurointerventionalists for endovascular ischemic stroke therapy. Neurology 79 (13 Suppl 1):S35-S41, 2012

48. Zou G: A modified Poisson regression approach to prospective studies with binary data. Am J Epidemiol 159:702-706, 2004

\section{Disclosures}

The authors report no conflict of interest concerning the materials or methods used in this study or the findings specified in this paper.

\section{Author Contributions}

Conception and design: Jahromi, Golnari. Acquisition of data: Golnari. Analysis and interpretation of data: Golnari, Nazari. Drafting the article: all authors. Critically revising the article: all authors. Reviewed submitted version of manuscript: all authors. Approved the final version of the manuscript on behalf of all authors: Jahromi. Statistical analysis: Golnari. Administrative/ technical/material support: Jahromi. Study supervision: Jahromi.

\section{Supplemental Information}

\section{Online-Only Content}

Supplemental material is available with the online version of the article.

Supplementary Materials. https://thejns.org/doi/suppl/10.3171/ 2019.12.JNS192755.

\section{Previous Presentations}

Portions of this work were presented in abstract form at the International Stroke Conference, Honolulu, Hawaii, February 6-8, 2019.

\section{Correspondence}

Babak S. Jahromi: Northwestern University Feinberg School of Medicine, Chicago, IL. bjahromi@nm.org. 